MIDAS

Museus e estudos interdisciplinares

$7 \mid 2016$

Varia

\title{
Da arte rústica à arte nacional: o Museu de Arte
} Popular

From folk art to national art: Museu de Arte Popular

\section{Carla Ribeiro}

\section{(2) OpenEdition}

Journals

\section{Edição electrónica}

URL: http://journals.openedition.org/midas/1074

DOI: $10.4000 /$ midas. 1074

ISSN: 2182-9543

\section{Editora:}

Alice Semedo, Paulo Simões Rodrigues, Pedro Casaleiro, Raquel Henriques da Silva, Ana Carvalho

Refêrencia eletrónica

Carla Ribeiro, «Da arte rústica à arte nacional: o Museu de Arte Popular », MIDAS [Online], 7 | 2016, posto online no dia 29 novembro 2016, consultado no dia 30 abril 2019. URL : http:// journals.openedition.org/midas/1074; DOI : 10.4000/midas.1074

Este documento foi criado de forma automática no dia 30 Abril 2019

\section{(c) (P) 80}

Midas is licensed under a Creative Commons Attribution-NonCommercial-ShareAlike 3.0 International License 


\title{
Da arte rústica à arte nacional: 0 Museu de Arte Popular
}

\author{
From folk art to national art: Museu de Arte Popular
}

\author{
Carla Ribeiro
}

\section{Introdução}

1 O século XX europeu nasceu sob o signo da insegurança, afastado das certezas de progresso indefinido da centúria de Oitocentos, situação agravada com a I Guerra Mundial. Politicamente, o mundo pós 1918 viria a ser o período de consolidação de ditaduras fascistas e de marcados nacionalismos um pouco por toda a Europa.

Em Portugal, a política do Estado Novo, oficializado em 1933, assumiu como missão restaurar a alma da pátria portuguesa e assegurar o prestígio da Nação. Para tal, foi criado logo nesse ano um organismo responsável pela propaganda de Portugal, do regime e do seu chefe, o Secretariado de Propaganda Nacional (SPN) ${ }^{1}$. o Secretariado, «plataforma centralizadora da política cultural oficial» (Melo 2001, 18), focou-se em particular na construção de um ideário que expressava a identidade da Nação portuguesa, naquilo que se propunha ser a sua autenticidade, estruturando uma memória coletiva, assente numa linguagem estética própria, que materializava a nova ordem política institucionalizada pelo regime. Construiu, assim, uma representação do país com repercussões a nível interno e externo: através da participação em exposições internacionais (como a de Paris, em 1937, ou a Feira Mundial de Nova Iorque, em 1939); da organização de exposições de arte popular (sendo a mais emblemática, porventura, a de 1940, no decorrer da Exposição do Mundo Português, através do Centro Regional então criado); da promoção de um conjunto de concursos populares (onde se destaca "A Aldeia mais Portuguesa de Portugal", de 1938); da edição de livros e revistas (como a obra Vida e Arte do Povo Português, de 1940, ou a Panorama, mensário iniciado em 1941) e da criação de estruturas artístico-culturais, como a companhia de bailados Verde Gaio ou o Museu de Arte Popular (MAP). 
3 Este artigo foca-se, pois, na questão da identidade nacional, centrando-se a análise no MAP. Propomos a tese de que o MAP nunca foi um museu, nem verdadeiramente o pretendeu ser, procurando dar resposta a uma série de questões de investigação: Que objetivos nortearam a criação do MAP? Como se passou de um Museu do Povo Português para um Museu de Arte Popular? Que ideia de Povo português foi a apresentada pelo Museu? Que ideia de Nação portuguesa foi concebida e exibida no MAP? A resposta ao conjunto de questões de investigação listadas mostrará que o MAP foi parte integrante da política de construção da fachada da nacionalidade, tal como a concebia o regime e o diretor do Secretariado, constituindo mais um dispositivo de identificação ideológica, espaço onde a cultura popular portuguesa aparecia desenhada com contornos folclorizados, simplificados, de forma a propagandear uma (inexistente) harmonia entre as classes sociais. A metodologia de trabalho adotada nesta análise teve por base a análise da documentação relativa ao MAP do fundo do SNI no arquivo da Torre do Tombo, tendose recorrido igualmente a fontes hemerográficas (imprensa diária e publicações periódicas), que permitiram compreender como foram recebidas as representações imagéticas fomentadas pelo Secretariado, através do MAP.

\section{O Secretariado de Propaganda Nacional e António Ferro}

4 A 25 de setembro de 1933, pelo decreto-lei n.. 23 054, foi fundado o Secretariado de Propaganda Nacional ${ }^{2}$. O organismo, pensado «no clima da nossa época» ("O Director do Secretariado da Propaganda Nacional” 1933, 5), ideia presente no preâmbulo do documento fundacional, nas referências feitas ao ambiente que então se vivia na Europa, aludia à necessidade de «todos os países novos ou renascentes organizar[em] e centralizar [em] a propaganda interna e externa da sua actividade» (Diário do Governo 1933, 1675). Além do mais, a propaganda constituía um meio privilegiado para criar e divulgar uma imagem: a imagem da própria Nação. Apesar dessa ideia, a de que a propaganda, nos Estados modernos, era um elemento fundamental, verificava-se ser «Portugal [...] o único país que não tinha ainda resolvido esse problema, deixando entregues as diversas manifestações da nossa actividade ao sabor das paixões nacionais e internacionais» (Diário do Governo 1933, 1675).

5 A 3 de outubro de 1933, então com 38 anos, António Ferro assumiu funções como diretor. $\mathrm{Na}$ altura sem carreira política, sem um diploma universitário (Ferro nunca chegou a terminar o curso de Direito), apenas com a fama de «voluntarioso intelectual» (ó 1999, 117). Ferro era «um dos homens da moderna geração mais admirados e mais discutidos» (“O Director do Secretariado da Propaganda Nacional” 1933, 5). Tendo vivido uma juventude artística de pendor essencialmente literário ${ }^{3}$ e participado na primeira geração de modernistas portugueses, destacou-se como jornalista, tendo trabalhado n'o Século (1920), no Diário de Lisboa (1921), na Ilustração Portuguesa (1922) e no Diário de Notícias (1924). Neste percurso, sobressaiu como entrevistador, realizando um conjunto significativo de entrevistas a personalidades internacionalmente conhecidas ${ }^{4}$.

61933 foi, desta forma, o momento-chave no percurso de Ferro, de conciliação da complexidade intrínseca da sua personalidade e das disparidades do seu trajeto, quando o literato e o jornalista, mesclados com um terceiro, o político, se tornaram num só. 
7 A partir da ideia inicial do presidente do Conselho, de um organismo que deveria servir como um espelho das realizações do regime - um espelho que não seria meramente refletor, mas também amplificador - Ferro criou uma instituição cuja tarefa seria a de dirigir e orientar toda a atividade cultural, através da definição de uma mística mobilizadora das massas. Neste sentido, o diretor do Secretariado não queria somente construir a imagem de Salazar, pretendia reconstruir a identidade cultural do país, criando uma nova consciência nacional.

\section{António Ferro e o Museu de Arte Popular}

8 A exposição de arte popular realizada em 1936 na sede do SPN, e por ele organizada, foi para Ferro o início da concretização de um programa idealizado desde o seu ingresso no organismo nacional de propaganda, relativo a um Museu do Povo Português:

Pena é [...] que esta colecção de objectos populares, tão laboriosamente conseguida, tenha de vir a ser enterrada em caixotes tumulares, sepultada até não se sabe quando. Os nossos esforços serão empregados desde hoje na criação dum grande museu do povo onde todas estas espontâneas obras-primas possam encontrar o seu lugar definitivo. (“A Exposição de Arte Popular Portuguesa” 1936, 1)

Pode inclusive remontar-se este sonho do diretor do Secretariado a 1935, à exposição de arte popular que fez parte da "Quinzena Portuguesa" organizada em Genebra:

Quando essa primeira Exposição de Arte Popular Portuguesa se inaugura, todos os que para ela contribuíram com o seu trabalho sentem e entendem que aquele núcleo será, fatalmente, o germe de alguma coisa maior e decisiva. Se essa foi a experiência inicial, novas tentativas se sucederam e a cada uma delas correspondia novo acréscimo de material necessário. (Maciel 1948, 1-2)

Ou, ainda, à ideia de um Museu do Povo Português, no final da I Guerra Mundial, em 1919, quando surgiu um plano para a construção de uma Aldeia Portuguesa na Flandres, nas proximidades de Richebourg L'Avoué, integrando um Museu Etnográfico Português, com risco de Jorge Segurado. A ideia passaria por devolver a pátria aos soldados nacionais mortos durante o conflito mundial em terras estrangeiras, sobretudo em La Lys, proporcionando, em simultâneo, o contacto com a história e a cultura portuguesas. Chegou-se a constituir um comité executivo, presidido pelo escultor Teixeira Lopes, e diversas figuras da vida pública portuguesa manifestaram o seu apoio, como Aquilino Ribeiro, que defendia a ideia «de um museu que seja o livro aberto lá fora, de nossas ignoradas e pitorescas províncias, [uma] obra eminentemente portuguesa, [pondo] ali o nosso Portugal a viver» (Ribeiro 1919a, 1). A iniciativa, contudo, ficou pela intenção, dado ter esmorecido o fervor político necessário à sua concretização.

No contexto da Exposição do Mundo Português (EMP), Luís Chaves ${ }^{5}$, um dos etnógrafos do regime, foi defendendo na rubrica "Nos domínios da Etnografia e do Folclore" e nas páginas da revista Ocidente, a criação de museus etnográficos nas capitais de província, que não deveriam ser «o museu erudito, hirto e seriado, para os estudiosos já iniciados, mas a figuração viva das coisas em quadros», espaços que ajudariam a que o povo se defendesse «contra a desnacionalização ou adulteração dos caracteres peculiares» (Chaves 1939, 159). Chaves destacava ainda a função educativa que estes museus provinciais deveriam assumir, esteios de uma pedagogia em ação. A sua proposta apresentava uma estrutura hierarquizada, a partir dos museus provinciais, que culminaria num grande museu nacional central, que pudesse fornecer «o panorama de 
todas as regiões em que se dividisse o território nacional, com a vantagem de por ele serem possíveis observações de conjunto e sínteses de expressão científica» (apud Bragança 2007, 128). O projeto, contudo, não teria imediato seguimento, mas pode-se especular que, de alguma forma, o MAP possa ter sido o corolário desta iniciativa falhada, o Museu que serviria de exemplo para os museus regionais que só mais tarde se concretizaram ${ }^{6}$.

Desta forma, embora pensado desde há muito, só depois de 1940, após a Exposição do Mundo Português, é que o projeto de Ferro adquiriu possibilidades efetivas de concretização, embora tenha sido ainda preciso esperar oito anos, até julho de 1948:

Mais intenso afã de investigação e recolha, mesmo de reconstituições, uma capacidade mais vasta de realização, garantida pelos correspondentes meios financeiros, consentiram, em 1940, quando das Comemorações Centenárias, a construção e o recheio dos pavilhões que formaram o Centro Regional no recinto da Exposição do Mundo Português. A semente de Genebra frutificou frondosamente em Belém. Ninguém ali deixou de se convencer de que aquela impressionante parada da rica e complexa e tão dispersa arte do nosso povo teria, pela força dominadora dos factos que se impõem, de passar de provisório, que a motivara, ao definitivo que no esforço despendido e os reais valores acumulados não só justificavam, mas também exigiam. (Maciel 1948, 1-2)

13 Que objetivos nortearam este desígnio de Ferro? Na realidade, o diretor do Secretariado viu no Museu a resposta a variados propósitos. Desde logo, o de educação da sensibilidade da população, a pedagogia do bom gosto portanto. Em simultâneo, numa vertente mais intelectual, o projeto dirigia-se à elite consumidora de cultura, procurando trazer até ao meio urbano a cultura popular. A finalidade maior, contudo, respondia à vontade da arte popular funcionar como uma espécie de laboratório para a criação artística nacional, isto é, como fonte inspiradora da renovação das artes plásticas e decorativas portuguesas: «[0] Museu fica sendo, portanto, se for bem aproveitado, uma nascente de arte moderna portuguesa, paleta para os pintores, pedra para os escultores, régua e compasso para os arquitectos, poesia para todos» (SNI 1948, 21).

Assim, o MAP seria um Museu vivo «de acção permanente e impulsionadora, destinado a revigorar aquelas forças criadoras que construíram a nacionalidade», não se destinando «somente a conservar mas a revelar o que é e o que vale o nosso povo, a mostrar Portugal aos portugueses» (ANTT - Secretariado Nacional de Informação 1944, cx. 4306).

Finalmente, para Ferro, este seria um Museu destinado a estimular «o artesanato português [pela] renascença de certas pequenas indústrias locais que já caíram em desuso» (“A Exposição de Arte Popular Portuguesa" 1936, 1)7 , lançando ideias como a da realização de um mercado de artesanato anexo ao Museu, através das quais se daria continuidade ao espírito que estivera associado ao Centro Regional da EMP ${ }^{8}$. Esta vontade de revitalização das indústrias populares, por intermédio do MAP, foi encarada como uma tarefa nacional, a partir da noção de certas elites intelectuais portuguesas, segundo as quais era necessário:

[...] reaportuguesar Portugal. Restitui-lo ao seu torrão nativo, à pureza dos seus costumes primitivos, posto de parte o receio de certos assustadiços e derrotistas, tementes de que tal renacionalização empecilhe o Progresso. Para abrirmos os braços ao futuro não necessitamos de despregar os olhos do passado. Antes pelo contrário, os exemplos de um servirão de lição ao outro. ("A Aldeia mais Portuguesa de Portugal" 1938, 2) 


\section{O Museu de Arte Popular}

16 Como se viu, o $\mathrm{MAP}^{9}$ começou verdadeiramente a desenhar-se depois das Comemorações Centenárias de 1940, aproveitando as estruturas criadas para o Centro Regional: em dezembro de 1941, o anúncio do concurso público para a empreitada de alteração dos pavilhões da Secção de Etnografia Metropolitana era publicado, tendo sido selecionado o arquiteto Veloso Reis Camelo, autor dos pavilhões originais.

Em 1942, entretanto, surgia uma proposta da Federação das Sociedades de Educação e Recreio ${ }^{10}$, que apelava à necessidade da criação em Lisboa de um museu de arte popular portuguesa, iniciativa considerada com «um fim puramente nacionalista» (ANTT Secretariado Nacional de Informação 1942a, cx. 266). O plano, exposto ao SPN para obtenção de apoio, deparou-se com a iniciativa estatal atrás referida já em andamento; em resposta, o organismo de Ferro chamou a si o monopólio da iniciativa: «A este Organismo incumbe, pelos seus serviços técnicos especializados e por determinação governamental, a organização dos planos e meios de se proceder à [...] instalação» do Museu (ANTT - Secretariado Nacional de Informação 1942b, cx. 266) ${ }^{11}$.

O primeiro projeto de alteração deu entrada no Ministério da Obras Públicas em março de 1942 e em abril Francisco Lage ${ }^{12}$ enviava a Ferro um documento de quatro páginas, criticando fortemente o projeto arquitetónico apresentado, pela ausência de uma memória descritiva e porque, no essencial, este lhe parecia apenas uma adaptação dos pavilhões para uma nova exposição e não a necessária transformação para um museu propriamente dito (Oliveira 2011, s/p). Em outubro, Lage fazia chegar a Ferro um novo documento, de 47 páginas, um plano de organização do Museu, que se analisará mais à frente.

19 No ano seguinte, em 1943 foi constituída uma comissão técnica e artística para a instalação do MAP, formada pelos artistas-decoradores do SPN: Bernardo Marques, Tomás de Mello (Tom) ${ }^{13}$, Carlos Botelho e Fred Kradolfer, que assinaram a memória descritiva do projeto definitivo de Jorge Segurado sendo, a 28 de julho de 1944, pelo decreto-lei n.. 33 820 , fixada uma verba de $1000000 \$ 00$ a despender com esse empreendimento.

Em 1945, Lage passa a chefe da 3.. Repartição da Cultura Popular do Secretariado ${ }^{14}$, arcando com a responsabilidade de organização e instalação do MAP. Do seu trabalho de preparação, destacam-se os contatos com figuras do meio académico nacional, convidando-as a elaborar textos para o Museu, e a compilação de mapas regionais de dialetos e flora local. Todavia, à medida que se aproximava a data de inauguração, é Tomás de Mello que progressivamente foi assumindo a direção da instalação do acervo, ocupando-se da disposição final dos objetos. Importa dizer que Tom parece ter sucedido nesta tarefa a Bernardo Marques, que dirigiu inicialmente a equipa de remodelação, enquanto consultor técnico da secção etnográfica do Museu, acumulando também as funções de coordenador do grupo de artistas-decoradores. Desta forma, Lage ficaria responsável apenas pelos contatos com os artífices locais e pela aquisição de novos objetos (Oliveira 2011, s/p).

21 O itinerário expositivo do Museu assentava num conjunto de oito espaços distintos, englobando salas de exposição e zonas comuns, destacando-se as cinco salas representativas das províncias: Entre Douro e Minho; Trás-os-Montes; Algarve; Beiras; Estremadura e Alentejo ${ }^{15}$. 
sentaneamente a esta idealização, o discurso expositivo proposto para o Museu delineava um espírito informal, afastado dos preceitos e normativos museológicos típicos, assente num registo acessível, essencialmente sensorial e imagético. Os materiais estavam dispostos por tipos de objetos, sendo os mais representados os utensílios domésticos, de decoração e os trajes regionais, peças conotadas com a arte popular. Valorizava-se, claramente, o pitoresco e o colorido. Centrados em torno de si próprios, os objetos expostos eram acompanhados de uma legenda que indicava a data, a autoria, a posse ou a origem (Lira 1996, s/p), contextualizados por frases-síntese de recorte poético, a maioria da autoria de Ferro, propositadamente criadas para o pavilhão nacional nas exposições internacionais de 1939 (em Nova Iorque e em S. Francisco). A tendência era, pois, para a descrição, mais do que para a narração ou interpretação. A acompanhar esta coleção de objetos, apresentar-se-iam pinturas murais de pendor modernista, representando o povo em cenários bucólicos, realizadas pela equipa artística do Secretariado: Manuel Lapa, Tomás de Mello, Eduardo Anahory, Carlos Botelho, Paulo Ferreira e Estrela Faria.

No MAP, procedeu-se à [re]utilização de técnicas usuais em exposições internacionais, desenvolvidas pela equipa do Secretariado, num modelo expositivo que se serviu de materiais simples, tradicionais até (arame, madeira, rede, metal, cortiça), em práticas inovadoras, que atualizavam as linguagens expositivas: pinturas decorativas, gráficos relevados, maquetas dotadas de movimento, dioramas, miniaturas, painéis pintados, divisórias em rede, tubos metálicos pintados, esculturas de arame, etc. Igualmente refletindo «esse sentido livre e informal [...], esse ambiente de festividade popular que caracteriza o Museu» (Bragança 2010, 115), estava o mobiliário criado propositadamente por Jorge Segurado e por Tom. Inspirado em características regionais, «nele está patente uma arte portuguesa, simultaneamente moderna e tradicionalista», através de mobiliário rústico, de linhas sóbrias e simples, normalmente em madeira de pinho ou carvalho, encerado de escuro, pontuado por aplicações de ferro forjado, com estes elementos de suporte a «estabelecer um elo de ligação entre as diferentes estruturas presentes, [numa] imagem coerente de conjunto e unidade» (Bragança 2010, 114-115).

Esta estilização e estetização eruditas dos objetos etnográficos expostos no MAP, desenvolvidas pelo SPN e pela equipa de artistas de Ferro, decorriam dos trabalhos realizados nesta área desde a I República, que tinha consagrado uma "etnografia artística", sendo a cultura demótica vista como sinónimo de arte popular, e veiculando-se uma intenção eminentemente visual das tradições populares, que deviam ser mostradas e celebradas com um interesse claramente focado nos objetos em si, mais do que no contexto por referência ao qual faziam sentido. 0 passado de que se falava era imemorial, atemporal mesmo, visto como algo que se procurava preservar e reativar no presente, projetando neste as qualidades estéticas e morais que lhe estariam associadas.

\section{As questões em torno do Museu de Arte Popular}

O MAP foi um híbrido, um lugar onde se mesclavam objetos tradicionais com estilizações modernistas de elementos populares, um espaço onde, como refere João Leal, «se misturavam diversos tempos - o tempo supostamente imóvel dos camponeses e o tempo moderno da construção autoritária das nações [e] diversos objetos - objetos populares 'genuínos', objetos populares encomendados, [...] murais de artistas modernistas» (Leal 2009 , 474). Esta conceção traduziu-se no facto de a maioria da coleção ser constituída por 
objetos encomendados (considerados cópias por nunca terem sido utilizados), embora houvesse igualmente objetos originais (usados pelo povo).

Obra de vanguarda no plano arquitetónico, a estética expositiva era igualmente inovadora. Os trabalhos dos artistas do Secretariado, à semelhança dos murais, corriam as paredes do Museu numa mancha gráfica que apresentava um forte pendor decorativo, podendo afirmar-se que o MAP revelava «o influxo positivo da experiência de design moderno aperfeiçoado em notáveis exposições e certames de feiras, nacionais e internacionais, da responsabilidade da equipa de decoradores do Secretariado de Propaganda Nacional» (Silva 2002, 85). Todavia, o mesmo não se passava com o discurso museográfico subjacente, parecendo ter-se retornado «às opções novecentistas do museu como gabinete de curiosidades, pressentindo-se um sentimento avesso ao vazio na exibição da coleção» (Ferreira 2008, 222).

Assim, entre a conceção, a estética e o discurso, pode afirmar-se que o MAP era uma montra, mais do que um Museu. As questões começaram logo nas próprias circunstâncias de constituição do acervo que depois integraria este espaço. Nesse processo colaborou «uma rede empenhada de agentes locais, alguns etnólogos regionais [...], utilizando metodologias de trabalho empíricas e pouco abertas à renovação que a etnologia estava então a conhecer» (Silva 2016, 105). Continuou na escolha dos autores da narrativa expositiva do Museu, centrada numa equipa de artistas (os artistas do Secretariado) e não em profissionais da museologia. Assim, apesar das intenções ou, pelo menos, do "manifesto" que orientou a sua criação, o MAP enfermava de uma metodologia de trabalho etnográfico rudimentar, sem profundidade, sem problematização, enaltecendo objetos de caráter lúdico e doméstico sobre os de trabalho, afastando-se dos preceitos e normativos museológicos europeus de então. Criou-se «um antimuseu» (Silva 2016, 106), essencialmente sensorial, falando predominantemente aos afetos. Depois, deve-se destacar o facto de o MAP não possuir reserva, sendo que toda a coleção estava exposta, pois todas as peças eram consideradas importantes, não existindo um critério de seleção, nem um efetivo cadastro, já que o inicial, realizado em 1935, restringia-se aos bens de algumas das salas, tendo sido apenas a partir de 1958 que a então conservadora do Museu, Madalena Cagigal e Silva, procedeu ao inventário de todo o acervo (Damasceno 2010).

Por fim, como anteriormente referido, o MAP encontrava-se na dependência direta do Secretariado, ao contrário dos restantes museus nacionais, tutelados pelo Ministério da Educação Nacional, o que lhe conferia, como salienta Raquel Henriques da Silva, uma existência marginal, afastando-o, porventura, da (necessária) organização científica dos demais museus do seu género pela Europa fora, que assentavam em sólido trabalho de terreno, com recolhas dele decorrentes, com registo fotográfico e fílmico, «no entendimento dos objetos como indicadores de civilização cujo contexto constitui o objetivo prevalecente» (Silva 2016, 95).

O MAP parecia, desta forma, ir de encontro à tese defendida pelo etnógrafo brasileiro Gustavo Barroso ${ }^{16}$, que em artigo no periódico A Manhã afirmava: «Uma das raízes que dão vida ao estudo do folclore é a nostalgia com que as classes superiores da sociedade volvem o olhar para a vida rústica [considerando que] a arte é mais acessível ao gosto e ao diletantismo do público urbano» (Barroso 1942, 3).

As opções museográficas assumidas no MAP, tornando-o «uma espécie de pavilhão de feira» (Silva 2016, 106), foram claramente percecionadas por todos. Fernando Pamplona, num artigo no Diário da Manhã, escrevia: 
Nunca um museu foi menos um museu do que este [...]. Acumulou-se, ordenou-se, seleccionou-se o mais rico e variado material etnográfico [...], disposto com graça, com inteligência, com subtileza, com intuição psicológica, com sentido decorativo porque, enfim, foi apresentado com arte. (apud Damasceno 2010, 98-99) 99).

Tal devia-se, como era referido, «ao grupo de artistas-decoradores que puseram de pé o Museu, que arrumaram as coleções sem lhes roubar o sal da vida» (apud Damasceno 2010,

Luís Chaves, por seu turno, na revista Panorama, criticava alguma das opções tomadas:

Goste-se ou não do Museu, como tal, acusem-no de não ser mais do que exposição sensacional com permanência de apresentação e continuidade de sentido próprio. Eu - confesso-o - não o formaria assim, mas aceito-o tal qual como está [...]. Perguntassem-me se é um Museu Etnográfico, diria imediatamente que sim [...]. Científico? Não, porque não o quiseram fazer desta feição. Falta-lhe a sistematização científica, porque lha não quiseram dar. (Chaves 1948, s/p)

Cedia, não obstante, ao inevitável da proposta ferrista, tornada realidade, do Museu como «o melhor cartaz de Portugal na vivacidade espontânea e sugestiva e característica da sua gente, [um] cartaz vivo, sem limites de pintura e de tipografia, [que] se defina em forma de Museu», dirigido a turistas, nacionais e estrangeiros, servindo assim «à maravilha o seu destino oficial», aceitando:

[...] plenamente que o Secretariado Nacional da Informação, por lhe caberem também funções de turismo e de propaganda das belezas e riquezas regionais da terra e da gente, nos tenha apresentado este plano de expressão colorida, pitoresca, e deliciosamente organizada. Foi lógico e foi coerente consigo. (Chaves 1948, s/p)

Todavia, o MAP fora entendido por outros, na sua fase de conceção, como a possibilidade de algo muito diferente. Pensa-se em particular na visão de Francisco Lage, e no documento anteriormente referido, de 1942, de 47 páginas, denominado Plano de Organização do Museu do Povo Português. Metodologicamente inovador, pois resultara de um conjunto de reuniões com vários etnógrafos para a organização do novo espaço museográfico, este plano distanciava-se de todos os eventos de caráter etnográfico realizados até então pelo SPN e, mesmo, dos que o próprio Lage havia organizado. Neste plano propunha-se um projeto racional para um museu etnográfico, com um esquema organizativo que se afastava do que veio a ser o MAP de Ferro.

Lage apresentava a organização do Museu em três secções principais: uma primeira zona de «Dependências de Acesso Público Constante», que incluía a sala de venda de artigos regionais e sete salas de exposição representativas das regiões portuguesas, segundo os limites administrativos das províncias; uma segunda grande secção, relativa às «Dependências de Acesso Público Condicionado», contendo a sala cultural, de uso exclusivo do Museu, para divulgação de atividades culturais específicas e para a projeção cinematográfica para um público mais restrito; aqui ficaria igualmente instalada uma sala de exposições temporárias; por fim, a última secção contemplava as áreas destinadas aos serviços administrativos, à biblioteca, arquivo, discoteca e filmoteca, aos serviços técnicos (gabinete dos serviços de conservação, laboratório técnico de conservação, restauro e execução, guarda-roupa) e aos armazéns (Bragança 2007).

O que Lage propunha era uma abordagem científica de conjunto do povo português, do ponto de vista antropológico e etnográfico ${ }^{17}$, revelando cada região através do meio e do Homem, apresentado pelas suas características antropológicas, da alimentação, da habitação, do trabalho, das manifestações sociais, etc. 
37 As diretivas estipuladas no referido plano apontavam para um cariz marcadamente concetual do Museu, através de uma noção expositiva do acervo, suportada por um conjunto de elementos testemunhais complementares e informativos, como fotografias, desenhos, plantas e reproduções, em tamanho natural ou por intermédio de reduções ${ }^{18}$, visando integrar os objetos, tanto quanto possível, no seu contexto original.

Idealizado por Lage como o Museu do Povo Português, quando foi inaugurado por Ferro, em 1948, era já o MAP. Como e a que se deveu tal transformação? Desde logo, a não concretização do ambicioso projeto de Lage dever-se-ia aos elevados custos financeiros que tal implicaria ${ }^{19}$, situação que prevaleceu na "versão alternativa" de Ferro, colocando mesmo em causa a continuação do projeto, de tal forma que, em 1947, se verificou uma paragem nas obras do Museu por falta de verba e a muito custo António Ferro conseguiu um aumento do valor previsto (relembre-se que este tinha sido fixado em $100000 \$ 00 \mathrm{em}$ 1944) para 1500 00\$00, a ser gasto em 1947 e 1948, sendo a verba do projeto elevada no seu total para $250000 \$ 00$ (Bragança 2007). Por outro lado, não são certamente de ignorar os constrangimentos de espaço verificados ${ }^{20}$.

O facto de ser a componente da arte popular a passar a ocupar lugar de destaque no Museu teria como justificativa o próprio acervo disponível, grande parte dele proveniente da Secção de Etnografia Metropolitana da EMP e das diversas exposições de arte demótica nacional organizadas por Ferro, tanto nacional como internacionalmente, bem como o papel fundamental desempenhado por Tomás de Mello, como coordenador do grupo de artistas-decoradores, a partir de 1946. De resto, Tom tinha sido o responsável pelas secções de arte popular nas várias exposições no estrangeiro em que Portugal tinha participado ${ }^{21}$, revelando-se um elemento-chave na conceção do mobiliário expositivo do Museu, na aquisição de peças e na encomenda de outras, bem como na montagem e na encenação dos artefactos, numa visão da arte popular que assentava, essencialmente, na procura da valorização estética dos objetos, por oposição às opções de cariz mais etnográfico de Francisco Lage.

Por fim, há que não esquecer que esta área da arte rústica tinha sido desde o início uma das pedras de toque do programa cultural do Secretariado, perfeitamente visível no luxuoso livro lançado em 1940 - Vida e Arte do Povo Português ${ }^{22}$. A arte popular aparecia como uma forma de «mergulhar na alma portuguesa» (Chaves e Marta 1936, 3), caracterizada pela «espontaneidade [...], singeleza, pureza, simplicidade» (Lage, Chaves e Ferreira 1940, 69), plena de poesia e ritmo, «fonte de riqueza espiritual» (Chaves e Marta 1936, 6). Efetivamente, para os responsáveis pela propaganda nacional, a arte popular provava a imutabilidade, a perenidade da Nação, «a linha recta donde provém, de épocas arcaicas, o sentido da lusitanidade, que é a própria e pura alma da Nação» (Lage, Chaves e Ferreira 1940, 81).

41 Resta, assim, a questão: até que ponto o projeto de Lage não colocaria em causa esta visão propagandística de Ferro?

\section{Considerações finais}

42 As linhas que antecedem estas notas finais partem de um princípio, no que à questão da construção da identidade diz respeito, considerando que, no Estado Novo, no período em apreço, esta foi construída no sentido de uma identidade fechada, de «absolutização do 
que é próprio», num percurso dominado "pelo ideal da autenticidade como pureza irredutível» (Moreira 2011, 23; 40-41).

Quanto aos museus, centro desta análise, considera-se que servem como instrumentos da memória (Silva 2002), partilhando-se da visão de Rhiannon Mason, quando refere que «desde o século XIX que a criação de instituições como os museus nacionais tem sido e continua a ser um ato de afirmação para os nacionalismos culturais», sendo que um Museu como o MAP pode ser entendido como «um movimento de consolidação e performance e, neste contexto, a história nacional é apresentada aos membros da nação como celebração e afirmação, mas também enquanto manual de instruções sobre o modo como estes se devem localizar a si próprios dentro da narrativa social» (Mason 2006, 131).

Apresentados os objetivos que nortearam a criação do MAP, destaca-se o enfoque dado à arte. Para Daniel Melo, «a arte, como produção cultural com maior potencial de visibilidade e valor simbólico, tornara-se o instrumento ideal para iluminar, para dar cor e sedução» (Melo 2001, 55) àquilo que era entendido como um projeto de ressurgimento nacional, levado a cabo pela "política do espírito" de Ferro. A ideia de uma arte nacional, «uma preocupação maior no final do século XIX», tornou-se «um desígnio obsidiante durante o Estado Novo» (Rosmaninho 2010, 522), tendo sido o diretor do Secretariado o responsável pela institucionalização da arte popular, numa apropriação altamente seletiva, como destaca Alves (2011), tendo-a elevado à categoria de arte nacional. Esta escolha tinha como primordial intenção estabelecer uma continuidade com o passado nacional, entendido como o passado rural, numa criação ideologicamente ancorada no presente e que procurava representar a expressão da autonomia espiritual da Nação.

Considerando, então, os museus como instituições que guardam e comunicam seletivamente informação, espaços que participam ativamente na criação de identidades e, portanto, se apresentam como espaços de poder, de um discurso de poder, o MAP foi, desta forma, o instrumento que possibilitou a criação de uma imagem do país como «retrato da alma de um povo que não quer renunciar nem à sua graça nem ao seu carácter» (SNI 1948, 15). Projetando um olhar cenográfico sobre a cultura popular, assumiu-se como um espaço de articulação entre tradição, modernidade e nacionalismo.

Pode mesmo afirmar-se que o MAP alicerçou a sua estruturação na noção de nacionalidade mais do que num caráter científico, procurando a recriação de uma arte decorativa nacional oficial, sustentada no valor folclórico e propagandístico da arte rústica, reinterpretada pela criação artística de vanguarda e apresentada como emblema de afirmação nacional:

[Este] não é apenas um Museu [...] onde as coisas venham a encher-se de pó e de bolor, é também, ou sobretudo, um museu poético, o museu da poesia esparsa, inata do povo português, da terra portuguesa [...], fonte de inspiração para os nossos artistas, [que] na valorização da arte popular, na sua transposição para o plano decorativo, começaram a inspirar-se nos seus motivos, a renová-los sem lhes fazer perder o carácter. (SNI 1948, 17; 22; 25)

Esta aceção manifestava-se ainda em 1962, com Madalena Cagigal e Silva, conservadora do MAP, ao afirmar que os museus de arte popular serviriam «de propaganda e conhecimento do País no estrangeiro» (apud Damasceno 2010, 106).

Esta praxis fez com que o coletivo português emergisse como um povo filtrado, depurado, pronto a cumprir o seu papel no dispositivo político-ideológico então prevalecente, um ente idealizado, imobilizado no tempo, folclorizado, que habitava um espaço rural utópico, sem contradições ou sofrimento, afastado de todas as influências estrangeiras, 
desnacionalizantes. Esta cultura popular e este povo estariam, assim, associados aos vestígios das sociedades pré-industriais, núcleos de sobrevivência assentes na pureza e imutabilidade.

Para esta imagem do povo, a abordagem centrada nos objetos, enquanto elementos meramente ornamentais, em detrimento dos agentes produtores, revelou-se essencial, uma vez que, como refere Joaquim Pais de Brito:

[...] o objeto etnográfico está no centro de um paradoxo que permite fazê-lo destacar na sua excelência formal e plástica [através da] apreciação estética [exterior] ao universo cultural em que foram produzidos; e, em simultâneo, vão sendo desarticulados da relação com os outros artefactos do contexto cultural a que pertencem. Há um crescendo da valorização da obra singular, ou mesmo única, por oposição à obra representativa de uma prática [...], de um universo de representações que sempre caracterizou o documento etnográfico. (Brito 2005, 157)

Esta noção de povo português, assente na ruralidade e nas suas tradições, aliava-se a um nacionalismo fortemente historicista, enfatizando-se a antiguidade da Nação. A estes dois vetores estruturantes, unificadores e identitários - história e tradições - juntava-se um terceiro, relativo à dimensão territorial, de um Portugal imperial, «do Minho a Timor», promovido em diversos momentos, em particular através das exposições e das comemorações, como a Exposição Colonial do Porto (1934), a Exposição Histórica da Ocupação (1937) ou a Exposição do Mundo Português (1940), através da Secção de Etnografia Ultramarina de Henrique Galvão.

51 Em jeito de conclusão, para Ferro e para o seu Secretariado, que assumiu a tarefa de (re)elaboração da retórica identitária nacional, a conciliação entre tradição e progresso, entre passado e presente nacionais inspirava o seu programa de nacionalização do mundo português.

\section{BIBLIOGRAFIA}

“A Aldeia mais Portuguesa de Portugal.” 1938. Diário de Notícias, 6 de setembro, p. 2.

“A Exposição de Arte Popular Portuguesa.” 1936. Diário de Notícias, 5 de junho, p. 1.

“O Director do Secretariado da Propaganda Nacional." 1933. Diário de Lisboa, 11 de outubro, p. 5.

“O Museu Etnográfico da Aldeia Portuguesa.” 1919. Diário de Notícias, 6 de novembro, p. 1.

Alves, Vera Marques. 2007. "Camponeses Estetas no Estado Novo: Arte Popular e Nação na Política Folclorista do Secretariado da Propaganda Nacional.” Tese de doutoramento em Antropologia, Instituto Superior de Ciências do Trabalho e da Empresa do Instituto Universitário de Lisboa.

Alves, Vera Marques. 2011. “O Estado Novo, a Etnografia Portuguesa e o Museu de Arte Popular.” Comunicação apresentada no I Ciclo de Conferências do MAP Memórias e Ativações Patrimoniais, Lisboa. http://www.fundacaoantonioquadros.pt/index.php? option=com_content\&task=view\&id=65\&Itemid=69\&limit=1\&limitstart=20 
ANTT - Secretariado Nacional de Informação. 1942a. "Carta do Presidente da Direção da Federação das Sociedades de Educação e Recreio ao SPN.” cx. 266, 23.2.1942, p. 1.

ANTT - Secretariado Nacional de Informação. 1942b. "Carta do SPN ao Presidente da Direção da Federação das Sociedades de Educação e Recreio.” cx. 266, 29.4.1942, p. 1-2.

ANTT - Secretariado Nacional de Informação. 1944. "Vai ser Criado em Lisboa o Museu do Povo Português". Diário Popular, cx. 4306, 14.9.1944.

Barroso, Gustavo, 1942. “Em Torno da Criação de um Museu Ergológico Brasileiro”. A Manhã , 29 de dezembro: $3 ; 5$.

Bragança, Maria de. 2007. "Museu de Arte Popular. Antecedentes e Consolidação (1935-1948)." Dissertação de mestrado em Museologia e Património, Faculdade de Ciências Sociais e Humanas da Universidade Nova de Lisboa.

Bragança, Maria. 2010. “Ascensão, Decadência e Reinvenção de um Museu: o Museu de Arte Popular (1948-2010).” Comunicação apresentada no II Seminário Investigación en Museologia de los Países de Lengua Portuguesa y Española, Buenos Aires, Argentina. http://ler.letras.up.pt/uploads/ ficheiros/10308.pdf

Brito, Joaquim Pais de. 2005. "O Museu, Entre o que Guarda e o que Mostra." In Museus, Discursose Representações, coordenação de Alice Semedo e João Teixeira, 149-161. Porto: Edições Afrontamento.

Chaves, Luís, 1939. “Museus de Etnografia.” Ocidente: Revista Portuguesa de Cultura 14: 159.

Chaves, Luís, 1948. “O Novo Museu de Arte Popular em Belém.” Panorama, Revista Portuguesa de Arte e Turismo I série (35): s/p.

Chaves, Luís, e Manuel Cardoso Marta, ed. 1936. Catálogo da Exposição de Arte Popular Portuguesa. Lisboa: SPN.

Damasceno, Joana, 2010. Museus Para o Povo Português. Coimbra: Imprensa da Universidade de Coimbra.

Decreto-lei n.․․ 23054 de 25 de setembro. Diário do Governo. I série, ․ํ218: 1675 (1933).

Decreto-lei n. 33820 de 28 de julho. Diário do Governo. I série, n.ำ 164 (1944).

Ferreira, Marta. 2008. “De Pavilhão de Exposição a Museu: O Museu de Arte Popular (1940-1948), Escola de Bom Gosto." Monumentos, Revista Semestral do Património Construído e da Reabilitação Urbana 28: 214-224.

Lage, Francisco, Luís Chaves, e Paulo Ferreira. 1940. Vida e Arte do Povo Português. Lisboa: SPN. Leal, João. 2009. “Da Arte Popular às Culturas Populares Híbridas.” Etnográfica 13 (2): 467-480. Lira, Sérgio. 1996. “O Nacionalismo Português e o Discurso Museográfico: Linhas de Investigação.” Comunicação apresentada no III Congresso Historia da Antropoloxia e Antropoloxia Aplicada, Pontevedra, Espanha. http://www2.ufp.pt/ slira/artigos/comunicacaopontevedra.htm Maciel, António, 1948. "Nascimento e Maioridade de um Museu." Diário de Notícias, 14 de julho, p. $1-2$.

MAP. 2015. "Francisco Lage.” Consultado em março 9. http://www.map.imc-ip.pt/pt/index.php? $\mathrm{s}=$ white\&pid=289\&identificador=

MAP. 2015. “Tomás de Mello.” Consultado em março 9. http://www.map.imcip.pt/pt/index.php? $\mathrm{s}=$ white\&pid=340\&identificador $=$ 
Mason, Rhiannon. 2006. “Representar a Nação no Museu da Vida Galesa." In Patrimónios e Identidades. Ficções Contemporâneas, organizado por Elsa Peralta, e Marta Anico, 131-146. Oeiras: Celta.

Matriz PCI. “Luís Chaves.” 2015. Consultado em março 9. http://www.matrizpci.dgpc.pt/ MatrizPCI.Web/Inventario/Entidades/EntidadesConsultar.aspx?IdReg=447

Melo, Daniel. 2001. Salazarismo e Cultura Popular (1933-1958). Lisboa: Imprensa de Ciências Sociais. Moreira, Carlos Diogo. 2011. “Identidade e Pluralismo." In Identidade Nacional. Entre o Discurso e a Prática, coordenação de Maria de Fátima Amante, 37-45. Porto: CEPESE/Fronteira do Caos Editores.

Ó, Jorge Ramos do. 1999. Os Anos de Ferro: O Dispositivo Cultural Durante a "Política de Espírito" (19331949): Ideologia, Instituições, Agentes e Práticas. Lisboa: Editorial Estampa.

Oliveira, Alexandre. 2011. "Uma Abordagem Preliminar a 60 anos do Museu de Arte Popular." Comunicação apresentada no I Ciclo de Conferências do MAP Memórias e Ativações Patrimoniais, Lisboa, Portugal. http://www.fundacaoantonioquadros.pt/index.php? option=com_content\&task=view\&id=65\&Itemid=69\&limit=1\&limitstart=2

Pomar, Alexandre. 2009. “MAP 1 - A Exposição de 1940, o MAP e a Área de Belém.” Blogue Alexandre Pomar, 9 de janeiro, http://alexandrepomar.typepad.com/alexandre_pomar/2009/09/ map-1-.html

Ribeiro, Aquilino, 1919. “Museu da Aldeia Portuguesa.” Diário de Notícias, 5 de Outubro, p. 1. Rosmaninho, Nuno. 2010. “Arte Nacional: Conceito e Funcionalidade.” In Outros Combates pela História, coordenação de Maria Manuela Tavares Ribeiro, 521-527. Coimbra: Imprensa da Universidade de Coimbra.

Silva, Raquel Henriques da. 2002. "Os Museus: História e Prospectiva." In Panorama da Cultura Portuguesa no Século XX, coordenação de Fernando Pernes, 63-108. Porto: Edições Afrontamento e Fundação de Serralves.

Silva, Raquel Henriques da. 2016. "O Museu de Arte Popular, uma Herança à Procura de Futuro." In António Ferro: 120 Anos Depois, coordenação de Mafalda Ferro, 97-110. Lisboa: Texto Editora.

SNI. 1948. Museu de Arte Popular. Lisboa: Secretariado Nacional de Informação, Cultura Popular e Turismo.

Thiesse, Anne Marie. 2000. A Criação das Identidades Nacionais. Lisboa: Temas e Debates.

\section{NOTAS}

1. Alvo de operações de cosmética em 1944, perto do final da II Guerra Mundial, o SPN passou a Secretariado Nacional de Informação, Cultura Popular e Turismo (SNI) e, no período marcelista, em 1968, transformou-se em Secretaria de Estado de Informação e Turismo (SEIT).

2. No horizonte da criação do Secretariado estiveram dois outros organismos: o Reichsministerium für Volksanfklärung und Propaganda, da Alemanha nazi, dirigido por Joseph Goebbels, e o Sottosegretariato per la Stampa e la Propaganda, da Itália de Mussolini, surgidos igualmente neste ano. Instituições estatais, o Reichsministerium e o Sottosegretariato constituíram-se como elementos de controlo dos meios de comunicação e das manifestações culturais, eliminando quaisquer formas de expressão que se pudessem opor à leitura unilinear da realidade veiculada pelos respetivos regimes. Além desta função repressiva, os dois órgãos tinham a seu cargo o vetor da propaganda, eminentemente visual em ambos os casos, apelando a 
meios como o cartaz e o cinema - de forte pendor emocional e simbólico - e patente em eventos públicos, como as exposições, em geral de cariz comemorativo.

3. Na primeira metade da década de 1920, Ferro dividiu-se, a nível literário, entre a poesia e a conferência, a novela e o conto, o teatro e o manifesto. Desta sua carreira destacam-se as obras Teoria da Indiferença (1920), livro de aforismos e paradoxos sobre a arte, a vida e os homens, o romance Leviana (1921), que desenhava o perfil de uma mulher mundana, urbana e moderna, o manifesto modernista Nós (1921) e a peça Mar Alto (1922).

4. Desta série de entrevistas, publicadas sob o título de Viagem à Volta das Ditaduras, em 1927, destacaram-se as realizadas a Gabriel d'Annunzio, ao serviço de O Século e, a partir de 1924, já no Diário de Notícias, a políticos como Mussolini, Miguel Primo de Rivera ou Mustapha Kemal, entre muitos outros.

5. Luís Chaves (Chaves, 1888-(?)1975) foi um reconhecido escritor, arqueólogo e filólogo. Formado em Estudos Matemáticos pela Escola Politécnica e pela Universidade de Coimbra, ficou conhecido, todavia, pela sua atividade como etnógrafo. O seu percurso ficou marcado pela atividade que desenvolveu no Museu Etnológico Português desde 1912, quando foi nomeado preparador do Museu, ascendendo, com a saída de Vergílio Correia, a conservador interino em 1916. Afastado do museu em 1919, devido às suas filiações monárquicas, regressou ao cargo de conservador em 1931, após concurso público, onde permaneceu até 1957, data da sua aposentação. Figura central na etnografia da I República, tendo a sua produção se centrado no estudo da arte popular e cultura material, assumiu um lugar de destaque como colaborador oficial da ação folclorista do SPN (Matriz PCI 2015).

6. Como exemplos, indicam-se o Museu Provincial de Etnografia da Beira Alta (1943) e o Museu de Etnografia e História Provincial do Douro Litoral (1945).

7. De destacar que o aparecimento de museus etnográficos na Europa, desde o final do século XIX, foi marcante porque forneceu aos artistas e artesãos modelos e motivos para alimentar uma arte rústica nacional - decorrente da concorrência económica da produção industrial, e após um trabalho de adaptação guiado por artistas, o fabrico de objetos artesanais, provenientes do mundo rural, tornou-se uma produção valorizada, destinada a um público consumidor que ia desde a pequena burguesia nacional até a um público internacional abastado. Para a difusão deste artesanato rústico de luxo contribuíram as revistas especializadas, que forneciam, desta forma, a base identitária que conferia valor cultural a estas representações campesinas, pela associação entre antigo e nacional (Thiesse 2000).

8. Esta ideia terá sido concretizada apenas após a saída de Ferro do Secretariado, através do "Mercado da Primavera", evento que se realizou nos espaços em volta do MAP de 1965 a 1974, de caráter anual, incluindo uma feira de artesanato, restaurantes regionais e espetáculos de folclore. A partir de 1975, o "Mercado da Primavera" cedeu lugar ao "Mercado do Povo", a funcionar durante todo o ano, desativado em 1981-1982 (Pomar 2009).

9. A inspiração para um espaço como o MAP poderá ter vindo dos museus que apareceram na Europa Central e do Norte desde a década de 1860, como extensões permanentes dos ambientes etnográficos criados nas exposições internacionais, de que eram exemplos o Museu Nórdico, na Suécia (1880); o Museu Nacional de Etnografia da Dinamarca (1885) ou o Museu dos Trajes Alemães e Utensílios Domésticos Populares em Berlim (1894). No geral, os fundadores destes museus de etnografia nacional, desde finais do século XIX até ao período de entre as guerras mundiais, assumiram o empreendimento com o intuito de «acordar e estimular os sentimentos patrióticos do visitante» (Thiesse 2000, 199). 
10. De acordo com Melo (2001), no campo do associativismo cultural-recreativo, fora do espetro do Estado, no contexto da sociedade civil, portanto, a Federação das Sociedades de Educação e Recreio, instituição de origem republicana e de cunho independente, fundada em 1924, com sede em Lisboa, era vista pelo regime como uma forte ameaça à sua política cultural, tendo na FNAT (Fundação Nacional para a Alegria no Trabalho) o organismo que maior resistência opôs à sua ação.

11. A resposta do SPN deixava, contudo, ficar a porta aberta para uma colaboração entre as duas entidades, no que à recolha de espólio dizia respeito: «Este Secretariado espera poder contar com a valiosa colaboração dessa Federação, que terá então ensejo de consubstanciar o seu espírito de iniciativa e de dedicação pelas belas tradições de Portugal, tão galhardamente anunciadas e provadamente defendidas» (ANTT Secretariado Nacional de Informação 1942b, cx. 266).

12. Francisco Lage (Lisboa, 1888-1957), etnógrafo e folclorista, funcionário do Secretariado e diretor do MAP (desde a inauguração até à sua morte), mas também dramaturgo e argumentista. Foi o responsável pela conceção das exposições de caráter etnográfico e folclorista do Secretariado entre 1935 e 1944: organização e seleção do espólio de arte popular apresentado nas Exposições Internacionais de Paris (1937), Nova Iorque e S. Francisco (1939), de Madrid (1943) e do Centro Regional na Exposição do Mundo Português (1940). Foi diretor da dramaturgia do Teatro do Povo (1936) e colaborou com a companhia de bailados Verde Gaio (MAP 2015).

13. Tomás José de Mello (Rio de Janeiro, 1906-Oeiras, 1990) foi um artista multifacetado, pintor, desenhador, ilustrador e decorador. Colaborou como caricaturista na Voz e Diário da Manhã, como ilustrador na publicação infantil o Papagaio (1935) e na revista Ilustração e foi diretor da revista Cinelândia (1928); integrou a equipa de decoradores do restaurante Coq d'Or, no Chiado (1930), e assumiu a direção da Galeria UP (1934). Participou, desde 1937, em todas as exposições de arte moderna realizadas pelo Secretariado, tendo integrado as equipas de decoradores enviadas às grandes exposições internacionais no estrangeiro, sendo responsável pela decoração e montagem das salas do artesanato. Foi autor da cenografia e de figurinos para os bailados do Verde Gaio (MAP 2015).

14. Tendo a seu cargo as secções de etnografia, exposições, cinema, teatro e música.

15. Também o anteprojeto de Jorge Segurado, para o Museu Etnográfico, em 1919, compreendia oito salas, em volta de um átrio central, sendo cada sala decorada com o caráter da província correspondente, prevendo ainda uma seç̧ão para as ilhas e outra para as colónias. A arquitetura era «caracterizadamente portuguesa», com um alçado onde se salientava «o alpendre acolhedor que abriga a entrada do edifício, o qual é precedido de uma pequena escadaria. Por cima do alpendre há uma grande mancha de azulejos recortados a azul e amarelo. Este corpo central é coroado por um motivo de volutas, bem português, coberto com telhas de canudo» ("O Museu Etnográfico da Aldeia Portuguesa" 1919, 1). Ideias, como se depreende, muito semelhantes ao MAP concebido por António Ferro.

16. Gustavo Barroso (Fortaleza, 1888-Rio de Janeiro, 1959) foi advogado, escritor, etnógrafo. Fundador e diretor do Museu Nacional de História brasileiro (1922), presidente da Academia de Letras do Brasil, membro da Academia Portuguesa de História de Portugal, da Academia das Ciências de Lisboa e da Royal Society of Literature londrina, representou o Brasil em numerosas missões ao estrangeiro, como nas Comemorações dos Centenários de Portugal, em 1940 (Bragança 2007).

17. Isto embora contemporizasse, na proposta apresentada, com a via puramente estetizante de Ferro, numa espécie de compromisso, assumindo que valores como «a arte, o pitoresco, e a imaginação» serviriam para valorizar e não para absorver ou apagar, atuando-se assim «à sombra 
protetora do bom gosto, com o intuito de "suavizar" as aparências mais duras» (apud Bragança 2007, 126).

18. Como exemplo, relativamente ao interior das casas rústicas, Lage sugeria que se apresentassem «realizações completas, naturais se o espaço o permitir, ou em vulto reduzido, no caso contrário, e obedecendo a uma escala rigorosa de proporções, sendo o critério de escolha condicionado pelo valor representativo e pelo critério documental» ( apud Alves 2007, 158).

19. O projeto do MAP estava na dependência do Ministério das Obras Públicas, e da verba anual por ele imposta, bem como sujeito ao visto do Tribunal de Contas.

20. Apesar das mudanças efetuada ao seu plano, Lage não desistiu e logo após a inauguração, e depois de assumir o cargo do diretor do MAP, enviou a Ferro um plano de melhoramento e ampliação do Museu, lembrando ao diretor do Secretariado que, tal como estava, o Museu «não era um museu mas apenas uma montra» (apud Oliveira 2011, $\mathrm{s} / \mathrm{p})$.

21. A sua dedicação e gosto pela arte popular tinham-no levado a viajar pelo país desde finais dos anos 1930, tendo deixado, em resultado dessas viagens, um grande número de fotografias de paisagens, personagens e seus trajes, animais e feiras, etc.

22. Da autoria de Luís Chaves e Francisco Lage e ilustrado por Paulo Ferreira.

\section{RESUMOS}

A elaboração identitária realizada durante o Estado Novo, através de António Ferro, diretor do Secretariado de Propaganda Nacional, centrou-se na procura de elementos diferenciadores. Neste sentido, a cultura popular e, em particular, a arte rústica, revelaram-se elementos fundamentais na definição de cultura e de nação portuguesa. Em julho de 1948 era inaugurado, na zona de Belém, o Museu de Arte Popular (MAP), iniciativa de Ferro e o corolário de um programa estatal em torno do património demótico e do passado, que vinha sendo trabalhado desde 1935 pelo Secretariado. O MAP apresentava-se como um híbrido, um lugar onde se podiam encontrar objetos tradicionais em convivência com estilizações modernistas de elementos populares, apresentando uma arte decorativa nacional sustentada na arte popular. Este artigo procura entender o papel do MAP na propagandística do regime sobre as questões da identidade nacional, averiguando os propósitos da sua criação e que ideias de Povo e de Nação transmitiu. Para tal, a metodologia de trabalho adotada teve por base a análise da documentação relativa ao MAP do fundo do SNI no arquivo da Torre do Tombo, tendo-se recorrido igualmente a fontes hemerográficas (imprensa diária e publicações periódicas), que permitiram compreender como foram recebidas as representações imagéticas fomentadas pelo Secretariado, através do MAP. Assumindo como hipótese de trabalho que o MAP nunca foi verdadeiramente um museu, nem verdadeiramente pretendeu sê-lo, crê-se que a resposta a algumas das interrogações levantadas permitirá compreender até que ponto o MAP foi (mais) um instrumento de (re)criação identitária da Nação.

The identity building carried out during the period known as Estado Novo ("New State") by António Ferro, diretor of the Secretariado de Propaganda Nacional (National Propaganda Bureau), focused on the search for differentiating elements. In this sense, popular culture and, in 
particular, folk art, proved to be fundamental elements in the definition of the Portuguese culture and nation. In July 1948 was inaugurated in Belém the MAP - Museu de Arte Popular (Folk Art Museum) on Ferro's initiative. It became the point of arrival of a state program based on the demotic heritage and the past, which had been advancing since 1935. The MAP presented itself as a hybrid, a place where traditional objects coexisted with modernist stylizations of popular elements - the expression of a national decorative art based on folk art. This article seeks to understand the role of the MAP in the regime's propaganda regarding national identity, by investigating the purposes of its creation and the notions of Portuguese Folk and Nation which it conveyed. To this end, the methodology adopted was based on the analysis of the documentation regarding the MAP in the SNI Fund of the Torre do Tombo archives, and of printed sources (daily newspapers and periodicals), which allowed us to understand how the imagistic representations promoted by the Bureau, through the MAP, were received. Taking as a working hypothesis the idea that the Museum was never truly a museum, nor intended to be one, it is believed that the answer to some of the questions raised will allow us to understand the extent to which the Folk Art Museum was (yet another) instrument for (re)creating the national identity.

ÍNDICE

Keywords: national identity, folk art

Palavras-chave: identidade nacional, arte popular, Museu de Arte Popular, António Ferro, Secretariado Nacional de Informação

\section{AUTOR}

\section{CARLA RIBEIRO}

Doutora em História pela Faculdade de Letras da Universidade do Porto. Investigadora do Centro de Estudos da População, Economia e Sociedade (CEPESE) e do Centro de Investigação e Inovação em Educação (InEd). Tem como áreas de interesse, no âmbito da História cultural contemporânea, as políticas e os organismos culturais do Estado Novo, o cinema português no Estado Novo e os estudos folcloristas portugueses nos séculos XIX e XX, em ligação com as questões de identidade nacional. É docente na Escola Superior de Educação do Instituto Politécnico do Porto, desde 2005, na Unidade Técnico-Científica de Estudos Culturais e Sociais. Escola Superior de Educação, Politécnico do Porto, Rua Dr. Roberto Frias, 602, 4200-465, Porto, Portugal, carlaribeiro@ese.ipp.pt 